\title{
Risk Factors, Knowledge, Attitudes and Practices of Type 2 Diabetics Attending Industry, Campbellville Health Centers and West Demerara Hospital, Guyana
}

\author{
Tabitha Mallampati \\ School of Nursing, College of Medical Sciences, University of Guyana, Greater Georgetown, Guyana
}

Received January 18, 2021; Revised May 8, 2021; Accepted May 28, 2021

\section{Cite This Paper in the following Citation Styles}

(a): [1] Tabitha Mallampati, "Risk Factors, Knowledge, Attitudes and Practices of Type 2 Diabetics Attending Industry, Campbellville Health Centers and West Demerara Hospital, Guyana," Universal Journal of Public Health, Vol. 9, No. 3, pp. 131 - 139, 2021. DOI: 10.13189/ujph.2021.090304.

(b): Tabitha Mallampati (2021). Risk Factors, Knowledge, Attitudes and Practices of Type 2 Diabetics Attending Industry, Campbellville Health Centers and West Demerara Hospital, Guyana. Universal Journal of Public Health, 9(3), 131 - 139. DOI: 10.13189/ujph.2021.090304.

Copyright $@ 2021$ by authors, all rights reserved. Authors agree that this article remains permanently open access under the terms of the Creative Commons Attribution License 4.0 International License

\begin{abstract}
The objective of this study was to examine the risk factors, knowledge, attitudes, and practices of type 2 diabetic patients attending three health care facilities (Industry and Campbellville Health Centers and the West Demerara Regional Hospital) in Guyana, May and June 2019. This study utilized a quantitative, descriptive and cross-sectional approach. The sampling technique used was non-probability and purposive sampling. The participants included 114 diabetic patients attending three selected health centers in Guyana. The study used a pretested questionnaire to collect survey data. Data were analyzed using SPSS version 20.0. Statistical analysis methods were mean, median, standard deviation, percentages, cross-tabulation, p-value, chi-square, ANOVA and Friedman test. Study results indicated that risk factors such as age, ethnicity, family history, BMI had no significant relationship with the onset of diabetes among the study population. Findings revealed that the mean average of participants' RBS, BP, fasting blood sugar, HbA1C and lipid profile were high. Participants demonstrated an inadequate level of knowledge and practices. Some of the participants had challenges accessing specific laboratory tests and Insulin. Findings concluded that there is a critical need for improving diabetic knowledge and healthy practices among diabetic patients. Establishing culturally oriented and multi-sectoral diabetic self-care management programs is imperative to manage diabetes effectively.
\end{abstract}

Keywords Diabetes Mellitus, KAP, Risk Factors, Self-care Management

\section{Introduction}

Diabetes mellitus poses a significant public health challenge in the Caribbean region due to epidemiological and nutritional transition [1]. Lifestyle changes such as unhealthy dietary practices, physical inactivity, obesity and substance abuse significantly contribute to a higher incidence of diabetes and heart diseases in the Caribbean region [2]. More than 1 in 10 of the adult population of the Region of the Americas are affected with type 2 diabetes [3].

The overall prevalence of type 2 diabetes in the Caribbean region is estimated to be approximately $9 \%$. Diabetic related deaths are responsible for $13.8 \%$ of all deaths among adults in the region [4]. Trinidad and Tobago have the fifth-highest per capita rate of diabetes in the world and the highest in the western hemisphere [5]. In Guyana, approximately 24,000-36,000 people (8-12\% prevalence) are living with diabetes, 40,000-50,000 people (16-20\% prevalence) are living with hypertension, and 54,000-68,000 people are living with the two chronic diseases [6]. Studies indicate that Guyana has the second-highest prevalence (15.9\%) of diabetes in the 
Caribbean region [9, 24]. Notably, non-communicable diseases contribute to $70 \%$ of all deaths occurring in Guyana. These represent the leading cause of premature deaths before the age of 70 years [6]. However, research support that diabetes and diabetic complications are preventable with simple lifestyle modifications [3]. A holistic and culturally oriented diabetic education is a critical component of diabetic care [7]. Regular assessment of the risk factors such as BMI, laboratory tests, physical inactivity and unhealthy dietary practices provide an opportunity to assess diabetic patients' understanding of the disease and their ability to control it [8]. Attaining glycemic control, early detection of diabetic complications, assessing and managing comorbidities are critical components in diabetic management. Ongoing diabetic education of patients is imperative in managing diabetes and preventing diabetic complications [9]. Little research is available on the risk factors, knowledge, attitudes, and practices of type 2 diabetic patients attending Guyana's community health centers. Hence, the researcher designed this study to assess the risk factors, knowledge, attitudes and practices of type 2 diabetic patients attending three health centers in Region 3 and Region 4 communities. The data generated in this study will help to develop and establish holistic and multi-sectoral diabetic self-care management programs.

\section{Materials and Methods}

This study utilized a quantitative, descriptive and cross-sectional approach. The sampling method used was non-probability and purposive sampling. The participants included a total of 114 diabetic patients attending three health centers, including the Industry health center $(n=30)$, Campbellville health center $(\mathrm{n}=40)$ and the West Demerara Regional Hospital $(n=44)$. The Institutional Review Board, Ministry of Public Health, provided ethical permission to conduct this study. In addition, the Medical Director of the Georgetown Public Hospital Corporation and the Regional Health Officer, Region 3, provided permission to conduct this study. Prior permission was taken from the participants using consent forms. The researcher used the information provided in the literature reviews for developing a survey tool. Before administering the questionnaire, the researcher pretested the tool for validity and reliability purposes - the survey questionnaire comprised items regarding risk factors, knowledge, attitudes and practices related to diabetic care. The researcher administered the survey tool to the diabetic patients attending the selected health centers during May and June 2019. Inclusion criteria included patients with type 2 diabetes, and exclusion criteria included patients with type 1 diabetes and gestational diabetes. Data were analyzed using SPSS version 20.0. The study used statistical methods such as mean, median, standard deviation, percentages, cross-tabulation, p-value, chi-square, ANOVA and Friedman test to analyze the data.

\section{Results}

A total of 114 diabetic patients participated in this study. The mean age of the participants was $60 \pm 11$ years. Table 1 shows the participants' baseline characteristics and risk factors, such as ethnicity, BMI, comorbidity, and family history.

The duration of diabetic disease of the participants ranged from 1 year to 16 years. Results revealed that thirty-three percent (33\%) of the participants had diabetes for less than five years, and twenty-five percent (25\%) of the participants had the disease between 6-10 years.

Among the participants, $71 \%$ were female, and $29 \%$ of the participants were male. Chi-square test concluded that there was a significant relationship between participants' gender and diagnosed with diabetes since the p-value of 0.002 was less than the level of significance 0.05 .

The researcher used cross-tabulations to analyze the relationship between the participants' demographic characteristics, such as gender, ethnicity, BMI, family history, and disease duration.

Data showed that almost 31\% of the Afro-Guyanese were diagnosed with diabetes for more than 15 years. 34\% of the Indo-Guyanese were diagnosed with diabetes for less than five years. $50 \%$ of the Amerindians were diagnosed with diabetes for less than five years. Chi-square test concluded that there was no significant relationship between ethnicity and diagnosis with diabetes since the p-value of 0.275 was greater than the level of significance 0.05 .

Approximately $62 \%$ of participants with a BMI between 25.0 to 29.9 were diagnosed with diabetes for less than or equal to 5 years. In the study group, 37\% of the patients with a BMI between 18.5 to 24.9 were diagnosed with diabetes for 6 to 10 years. The chi-square test supported the hypothesis that there was no significant relationship between a patient's body mass index and that he/she was diagnosed with diabetes since the p-value of 0.322 was greater than the level of significance 0.05 .

Participants with a diabetic family history, about 30\%, were diagnosed with diabetes for less than or equal to five years. Whereas participants without a diabetic family history, approximately $44 \%$ were diagnosed with diabetes for less than or equal to five years. The Chi-square test supports the hypothesis that there is no relationship between family history and somebody diagnosed with diabetes. The p-value of 0.343 is greater than the level of significance 0.05 . 
Table 1. Descriptive Statistics of Demographic data

\begin{tabular}{|c|c|c|}
\hline Demographic Data & Participants $(\mathrm{N}=114)$ & Frequency \% \\
\hline \multicolumn{3}{|l|}{ Gender } \\
\hline Male & 33 & 29 \\
\hline Female & 81 & 71 \\
\hline \multicolumn{3}{|l|}{ Ethnicity } \\
\hline Afro-Guyanese & 35 & 31 \\
\hline Indo-Guyanese & 62 & 54 \\
\hline Amerindian & 6 & 5 \\
\hline Portuguese & 3 & 3 \\
\hline Other (specify) & 8 & 7 \\
\hline \multicolumn{3}{|l|}{ Marital Status } \\
\hline Single & 24 & 21 \\
\hline Married & 76 & 67 \\
\hline Common-Law Union & 8 & 7 \\
\hline Other & 6 & 5 \\
\hline \multicolumn{3}{|l|}{ Education } \\
\hline Primary & 64 & 56 \\
\hline Secondary & 42 & 37 \\
\hline Tertiary & 5 & 4 \\
\hline Other & 3 & 3 \\
\hline \multicolumn{3}{|l|}{ Employment } \\
\hline Working(full-time) & 21 & 18 \\
\hline Working(part-time) & 8 & 7 \\
\hline Unemployed & 3 & 3 \\
\hline Homemaker & 35 & 31 \\
\hline Retired & 28 & 25 \\
\hline Disabled & 12 & 10 \\
\hline Self-employment & 7 & 6 \\
\hline \multicolumn{3}{|l|}{ Duration of Diabetes } \\
\hline$\leq$ 5years & 38 & 33 \\
\hline $6-10$ years & 28 & 25 \\
\hline $11-15$ years & 21 & 18 \\
\hline$>15$ years & 27 & 24 \\
\hline \multicolumn{3}{|l|}{ Body Mass Index } \\
\hline$<18.5$ (Underweight) & 6 & 6 \\
\hline $18.5-24.9$ (Normal) & 30 & 26 \\
\hline 25.0-29.9 (Overweight) & 62 & 54 \\
\hline 30.0-39.9 (Obese) & 16 & 14 \\
\hline \multicolumn{3}{|l|}{ Comorbidity } \\
\hline Heart disease & 6 & 5 \\
\hline Stroke & 7 & 6 \\
\hline Arthritis & 19 & 17 \\
\hline Hypertension & 52 & 46 \\
\hline Any other disease & 30 & 26 \\
\hline \multicolumn{3}{|l|}{ Family History } \\
\hline High BP & 64 & 56 \\
\hline Diabetes & 78 & 68 \\
\hline Heart Problems & 13 & 12 \\
\hline High Cholesterol & 8 & 7 \\
\hline Asthma/ Allergies & 5 & 4 \\
\hline Cancer & 4 & 3 \\
\hline None & 5 & 4 \\
\hline Others & 11 & 9 \\
\hline
\end{tabular}


Table 2. Family history \& Diabetes: When was your diabetes diagnosed? Cross tabulation.

\begin{tabular}{|c|c|c|c|c|c|c|c|}
\hline & & & \multicolumn{4}{|c|}{ When was your diabetes diagnosed? } & \multirow[b]{2}{*}{ Total } \\
\hline & & & $\begin{array}{c}\text { Less than or } \\
\text { equal to } 5 \\
\text { years } \\
\end{array}$ & $6-10$ years & $\begin{array}{l}11-15 \\
\text { years }\end{array}$ & $\begin{array}{c}\text { More than } \\
15 \text { years }\end{array}$ & \\
\hline \multirow{4}{*}{$\begin{array}{c}\text { Family } \\
\text { history-Diabetes }\end{array}$} & \multirow{2}{*}{ No } & Count & 16 & 6 & 5 & 9 & 36 \\
\hline & & \% Within Family history-Diabetes & $44.4 \%$ & $16.7 \%$ & $13.9 \%$ & $25.0 \%$ & $100.0 \%$ \\
\hline & \multirow{2}{*}{ Yes } & Count & 23 & 21 & 16 & 18 & 78 \\
\hline & & \% Within Family history-Diabetes & $29.5 \%$ & $26.9 \%$ & $20.5 \%$ & $23.1 \%$ & $100.0 \%$ \\
\hline \multirow{2}{*}{ Total } & & Count & 39 & 27 & 21 & 27 & 114 \\
\hline & & $\%$ within Family-history-Diabetes & $34.2 \%$ & $23.7 \%$ & $18.4 \%$ & $23.7 \%$ & $100.0 \%$ \\
\hline
\end{tabular}

Results indicated that $75 \%$ received diabetic education from a health care professional, and $25 \%$ did not receive from any resources, including health care professionals, $\mathrm{TV}$, radio, brochure or family members.

Table 3 outlines a summary of diabetic complications participants are suffering.

Table 3. Complications of Diabetes

\begin{tabular}{|c|c|c|}
\hline Diabetes Complications & $\begin{array}{c}\text { Mean } \\
\text { Rank }\end{array}$ & Rank \\
\hline Diabetes complications - Eyes & 5.49 & 1 \\
\hline Diabetes complications - Kidneys & 4.3 & 5 \\
\hline Diabetes complications - Nerves or feet & 4.65 & 3 \\
\hline Diabetes complications - Heart & 4.51 & 4 \\
\hline Diabetes complications - Slowed digestion & 3.91 & 8 \\
\hline $\begin{array}{c}\text { Diabetes complications - Blocked arteries } \\
\text { in your legs }\end{array}$ & 4.19 & 6 \\
\hline Diabetes complications - No & 4.89 & 2 \\
\hline Diabetes complications - Do not know & 4.05 & 7 \\
\hline
\end{tabular}

From the Friedman test, participants suffer from, firstly, eye-related complications; secondly, no complications; thirdly, complications related to nerves or feet; fourthly, heart-related complications and kidneys associated complications.

The study explored the laboratory findings of the participants during the last 12 months. However, only the participants attending two health centers had access to all the laboratory tests and diabetic medications. One of the health centers did not have Insulin and resources to conduct necessary laboratory tests. Results showed that the participants' average laboratory findings such as BP, RBS, Fasting Blood Sugar, HbA1C, Triglycerides, Cholesterol, LDL, VLDL, and BUN Creatinine were high. Table 4 below displayed these findings.
Table 4. Patients' laboratory findings during the last 12 months

\begin{tabular}{|c|c|c|}
\hline Patients' current readings & Mean & Std. Deviation \\
\hline BP systolic & 132.34 & 21.718 \\
\hline BP diastolic & 78.46 & 9.583 \\
\hline RBS & 189.35 & 101.45 \\
\hline Fasting blood sugar & 156.48 & 73.418 \\
\hline HbA1C & 10 & 6.065 \\
\hline Triglyceride & 125.25 & 89.088 \\
\hline Cholesterol & 197.63 & 68.704 \\
\hline HDL & 37.59 & 13.486 \\
\hline LDL & 154.17 & 95.052 \\
\hline VLDL & 26.42 & 22.359 \\
\hline BUN & 13.68 & 6.039 \\
\hline Creatinine & 0.97 & 0.675 \\
\hline
\end{tabular}

\subsection{Knowledge}

The average knowledge score for the patients who participated in this study was 8.95 (SD \pm 1.876 ). The ANOVA test showed that the mean knowledge score among patients attending these three health centers was equal since the p-value of 0.313 was more than the level of significance 0.05 .

More than half of the participants (68\%) responded that eating too much sugar and other sweet foods was a cause of diabetes. Among 114 participants, (50\%) responded that medication was more important than diet and exercise to control their diabetes. In the study, $35 \%$ of the participants responded that the cause of an insulin reaction was too much food. Among the participants, 33\% of the respondents indicated that the diabetic diet consists primarily of special foods. 


\subsection{Attitudes}

Data revealed that the overall attitude of the participants regarding diabetic care was good. The attitude questions included (1) people with diabetes should learn a lot about the disease (2) the patient has more effect on his/her health status than anything that a doctor or nurse, or dietician can do (3) keeping the blood sugar close to normal can help prevent the complications of diabetes.

\subsection{Practices}

Table 5 displayed findings concerning practice questions related to exercise, diet and medication.

Table 5. Participants' response to practices

\begin{tabular}{|c|c|c|}
\hline Question & $\begin{array}{c}\text { Yes } \\
\mathbf{\%}\end{array}$ & $\begin{array}{c}\text { No } \\
\mathbf{\%}\end{array}$ \\
\hline $\begin{array}{c}\text { Do you exercise for at least 30 minutes } \\
\text { per day on at least four days of the } \\
\text { week? }\end{array}$ & 57 & 43 \\
\hline $\begin{array}{c}\text { Are you following a controlled diet } \\
\text { recommended by your nurse or doctor, } \\
\text { or dietician most of the time? }\end{array}$ & 65 & 68 \\
\hline $\begin{array}{c}\text { Do you often miss taking the doses of } \\
\text { your diabetic medication? }\end{array}$ & 32 & 68 \\
\hline
\end{tabular}

Among the participants, $43 \%$ of the patients do not exercise for at least 30 minutes per day for four days of the week. Participants provided various reasons for not following the diabetic diet recommended by health care professionals.

The Friedman test results in Table 6 demonstrated the ranking of various reasons for not following the participants' recommended diet.

Table 6. Reasons for not following the recommended diet

\begin{tabular}{|c|c|c|}
\hline $\begin{array}{c}\text { Reasons for not following } \\
\text { Controlled Diet }\end{array}$ & Mean Rank & Rank \\
\hline Practice- Financial & 3.28 & 3 \\
\hline Practice - Family - related problems & 3.2 & 5 \\
\hline Practice - Lack of time & 3.2 & 5 \\
\hline Practice - Too much trouble & 3.23 & 4 \\
\hline Practice - I do not like the food & 3.33 & 2 \\
\hline $\begin{array}{c}\text { Practice - I follow the recommended } \\
\text { diet }\end{array}$ & 4.75 & 1 \\
\hline
\end{tabular}

This study assessed other practices of diabetic patients, including regularly checking their blood pressure, blood sugar and feet examination. Among the participants, 58\% responded that they checked their blood pressure only during clinic visits.

\subsubsection{Checking Feet for Cuts and Abrasions}

Data revealed that $45 \%$ of the patients never checked their feet for cuts and abrasions. Figure 1 demonstrates the multiple comparisons on checking feet for cuts and abrasions.

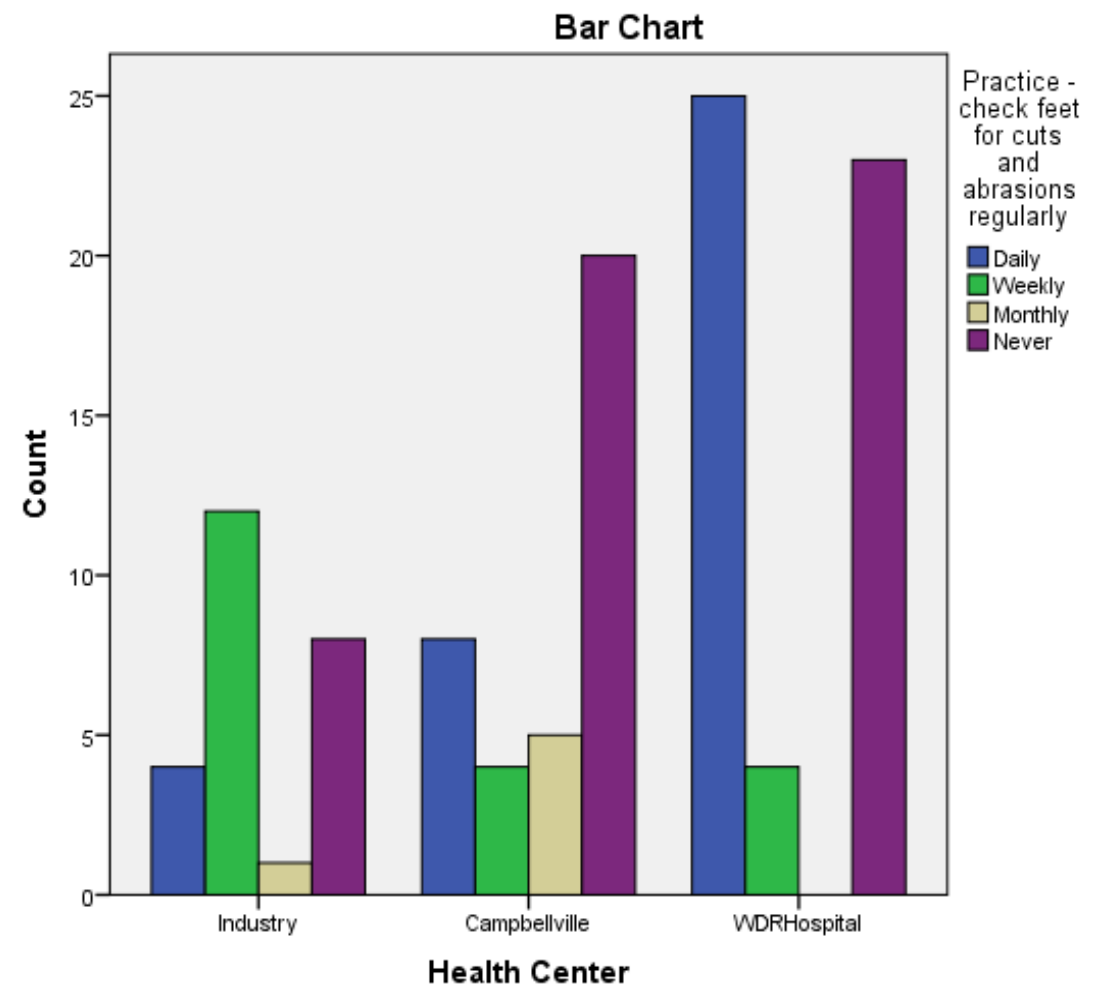

Figure 1. Check feet for cuts and abrasions - Multiple comparisons 


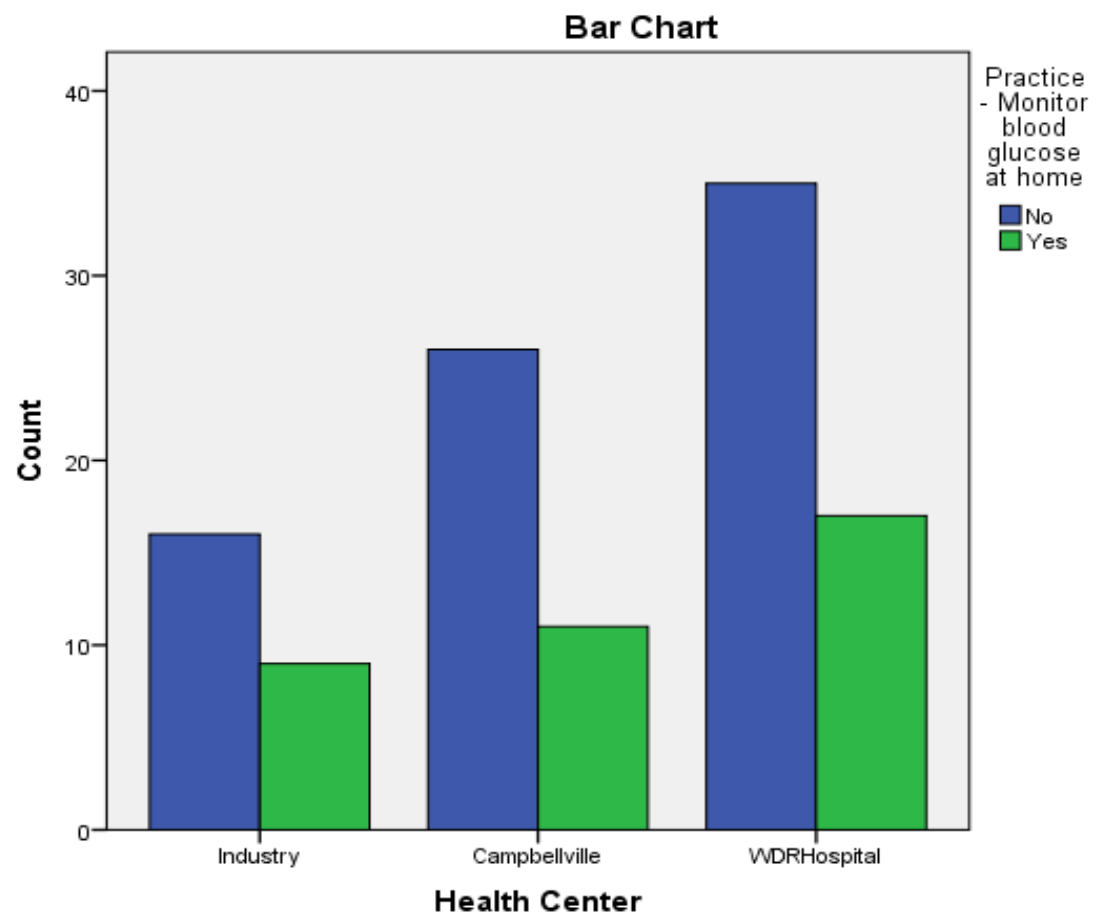

Figure 2. Monitor blood glucose at home-multiple comparisons

\subsubsection{Monitoring Blood Glucose}

Data revealed that $67 \%$ of the patients never monitored their blood glucose at home. The multiple bar chart in Figure 2 shows a comparison between the health care centers and patients monitoring their blood glucose level at home.

\section{Discussion}

Type 2 diabetes is a significant cause of morbidity and mortality in many countries. The estimation of the global prevalence of type 2 diabetes for all age groups was 2.8\% in 2000 and $4.4 \%$ in 2030 [13]. In Guyana, type 2 diabetes is the fourth leading cause of death, affecting $15.5 \%$ of the adult population [19]. Effective diabetic management includes training healthcare professionals, extending critical health care services and establishing self-care management programs. However, because of lack of access to health care services and awareness about diabetes, most diabetic patients suffer from complications [20]. This study has proven that patients' knowledge levels and practices attending these three health care centers were inadequate and similar.

Among the participants, $71 \%$ were female, and $29 \%$ were male. This finding was consistent with the other studies that diabetes has a high prevalence among women $[7,24]$. The chi-square test concluded that there was a significant relationship between gender and diagnosis with diabetes.

The data revealed that fifty-four percent (54\%) of participants were Indo-Guyanese, and thirty-one percent
(31\%) of the participants were Afro-Guyanese, seven percent $(7 \%)$ of the patients from other ethnic group and five percent $(5 \%)$ of the patients from the Amerindian community. This study's findings are similar to a survey held in Schenectady, New York, which confirmed the high prevalence of diabetes were among Indo-Guyanese adults [8]. On the other hand, this study's results support that most diabetes is increasing among other ethnic populations in Guyana [9, 20, 24].

During the last decade, similar to many Caribbean territories, the prevalence of diabetes has significantly increased in Guyana due to epidemiological transition [9, 20, 24]. This study observed that thirty-three (33\%) of the participants had diabetes for less than the last five years, and twenty-five (25\%) percent of the participants had the disease between 6-10 years. This trend indicates the growing prevalence of the disease among the Guyanese population.

Additionally, the data have proven that $24 \%$ of the newly diagnosed patients fall under the age group of less than 55 years. The results of this study support other studies that the prevalence of diabetes has been significantly escalating among the working-age population from all ethnic backgrounds in the Caribbean $[9,18]$.

Obesity is a significant risk factor for cardiovascular diseases among diabetic patients. The findings of this study revealed that more than half of the participants (54\%) in this study were overweight. The prevalence of obesity and sedentary lifestyle in Caribbean societies contributes to non-communicable diseases such as diabetes and heart diseases [12, 22]. 
Moreover, results indicate that the risk factors such as ethnicity, family history, and BMI had no significant relationship with the duration of diabetes since the p-value was greater than 0.05 . These findings support other research studies that diabetes prevalence is trending among all ethnic backgrounds due to epidemiological transition $[5,11,18]$.

Additionally, most participants in this study also suffered from comorbidities such as heart diseases, hypercholesterolemia and stroke. Most of the burden in the Caribbean region comes from medical conditions such as diabetes, cardiovascular disease, hypercholesterolemia, and cancers [12].

Research postulates that one of diabetic care's critical components is the early detection and treatment of diabetic complications $[9,20]$. This study recommends that a holistic, multi-sectoral and collaborative approach in addressing NCDs is imperative.

Results showed that the participants' average laboratory findings such as BP, RBS, Fasting Blood Sugar, HbA1C, Triglycerides, Cholesterol, LDL, VLDL, and BUN Creatinine were high. Some study participants lacked access to laboratory tests such as $\mathrm{HbA} 1 \mathrm{C}$ and lipid tests. Some participants could not have access to Insulin [13]. This limitation, if not corrected, will continue to hamper the effective management of the disease. The finding supports research highlighting that patients living in rural areas were at a greater disadvantage in accessing health care services and managing chronic diseases [15, 26].

Likewise, data indicated that the knowledge of participants regarding dietary practices was inadequate. Many patients (35\%) responded that they were not following a controlled diet recommended by a nurse or doctor, or dietician.

Some participants were not following the recommended diet due to uncontrolled food habits or financial challenges. Some participants responded that they do not eat fresh fish, vegetables, peas and beans regularly. Therefore, providing diabetic patients with ongoing, holistic, cost-effective, and culturally tailored dietary education is critical $[5,7,23]$.

Almost half of the patients (43\%) did not exercise for at least 30 minutes per day on at least four days of the week. Thirty-two (32\%) of the participants missed taking the dose of diabetic medication. Freidman test revealed that most participants checked their BP, RBS and feet for cuts only when visiting the clinics. These results were similar to another study done in Trinidad [5]. Also, results revealed that $27 \%$ of the participants never had their eye examination done. Besides, participants in this study lacked knowledge of diabetic diet, exercise and assessment of early symptoms of diabetic complications. These findings support another study conducted in Guyana, which projected that the KAP level of the diabetic population regarding complications attending the Diabetic Clinic of the Peter's Hall Jamat in Guyana was inadequate [24].
Although the doctors and nurses gave diabetic education at the clinic, the study participants demonstrated poor knowledge and inadequate self-care practices. Among the participants, 22\% of the patients responded that they did not receive any diabetic education.

Results indicated that effective and ongoing self-care management programmes for diabetic patients lacked among the study population. This study concludes that there is a paucity of ongoing culturally tailored diabetic self-care management programmes for diabetic patients in Guyana [5, 23]. A research study conducted on diabetic foot challenges in Guyana highlighted that patient education was the most effective tool that could assist with early detection, lessen complications, and assist with the management of diabetes [20]. Similarly, few global KAP studies on chronic diseases identified poor patient knowledge and inadequate practices for secondary prevention. Therefore, providing correct information and support for adopting good behaviours in the target population suffering from these diseases is critical [25, 26].

Clearly, in response to this need, a self-care management program should be a high priority intervention. Local studies showed that low health literacy was associated with higher HbA1C and random blood glucose [11, 19]. Several global studies proved that diabetes self-management education is an effective intervention strategy that enhances diabetic knowledge and provides the best treatment outcomes [11, 17, 23]. Likewise, studies established that the long-term complications of type 2 diabetes are preventable [11, 21]. A participatory action research study conducted in the UK among the Guyanese population successfully connected, engaged and socially empowered the participants by group therapy and participatory community approaches. [23]. Hence, establishing culturally tailored self-care management programs are critical interventions.

Research supports that inadequate training of health care workers and lack of ongoing diabetic education programs are critical challenges in managing diabetes care in Guyana [20]. For this reason, policymakers from the government and non-government agencies should collaborate and maximize human and material resources. Training programs for health care professionals in educating diabetic patients effectively at the primary healthcare level is imperative.

In summary, there is an urgent need for establishing comprehensive, multi-sectoral, collaborative, and innovative measures in combating diabetes effectively in Guyana. Hence, addressing these shortages on an emergency basis should be a priority.

\section{Conclusions}

In conclusion, this study showed that the knowledge and self-care practices of study participants are inadequate. 
Therefore, ongoing, holistic, culturally oriented self-care management programmes are critical in assisting diabetic patients in navigating complex decisions and activities to improve health outcomes.

\section{Acknowledgements}

The researcher of this study would like to thank all study participants, nurses and doctors who gave their full support and cooperation to conduct this study.

\section{REFERENCES}

[1] Pan American Health Organization. Health in the Americas+, 2017 Edition. Summary: Regional Outlook and Country Profiles, Washington, D.C.: PAHO; 2017. https://www.paho.org/salud-en-las-americas-2017/?tag=diab etes.

[2] Pan American Health Organization. Innovative Care for Chronic Conditions: Organizing and Delivering High-Quality Care for Chronic Noncommunicable Diseases in the Americas. Washington, DC: PAHO, 2013. https://www.paho.org/hq/dmdocuments/2013/PAHO-Innova te-Care-2013-Eng.pdf

[3] World Health Organization. Global Report on Diabetes. Geneva: WHO, 2016. https://apps.who.int/iris/bitstream/han dle/10665/204871/9789241565257_eng.pdf?sequence=1

[4] N. R. Bennett, D. K. Francis, T.S. Ferguson, A.J. Hennis, R. J. Wilks, E. N. Harris, M. M. MacLeish, L. W. Sullivan, U.S. Caribbean Alliance for Health Disparities Research Group (USCAHDR), "Disparities in diabetes mellitus among Caribbean populations: a scoping review," International Journal for Equity in Health, 14, 23, 2015. DOI: 10.1186/s12939-015-0149-z

[5] L. Beaubrun-Toby, "Knowledge, attitudes and practices of diabetics attending the Carenage Health Center, in St. George West, Trinidad," St. Augustine Campus Repository, 2014.

[6] Ministry of Health, Guyana, Guyana strategic plan for the integrated prevention and control of Chronic Non-communicable diseases and their risk factors 2013 2020.

www.paho.org/guy/index.php?option=com_docman...guyan a-ncds

[7] N. Gul, "Knowledge, Attitudes and Practices of type 2 diabetic patients," Journal of Ayub Medical College, Vol. 22, No.3, pp. 128-131, 2010.

[8] A.S. Hosler, D. S. Pratt, K. A. Sen, E. M. Buckenmeyer, A. Simao, E. E. Back, S. Savadatti, J. L. Kahn, G. S. Hunt, "High prevalence of diabetes among Indo-Guyanese adults, Schenectady, New York," Preventing Chronic Disease, 10, E43, 2013. DOI: 10.5888/pcd10.120211.
[9] R. Kurup, A.A. Ansari, J. Singh, "A review on diabetic foot challenges in Guyanese perspective," Diabetes \& Metabolic Syndrome, Vol. 13, No.2, pp. 905-912, 2019. DOI: 10.1016/j.dsx.2018.12.010.

[10] Pan American Health Organization, Regional Office of the World Health Organization: Guyana: Country Cooperation Strategy 2010 - 2015, Guyana, 2010. http://www.paho.org/ guy/index.php?option $1 / 4$ com_content\&view $1 / 4$ article\&id $1 / 468$ Guyana-ccs-2010-2015\&Itemid $1 \frac{1}{4} 0$.

[11]C. Tidy, "Assessment of the patient with established diabetes," patient, 2016.

[12] S. F. Yisahak, J. Beagley, I.R. Hambleton, K.M.V. Narayan, "Diabetes in North America and The Caribbean: An update," Diabetes Research and Clinical Practice, Vol103, pp. 223 $-230,2014$

[13] M. S. Boyne, Diabetes in the Caribbean: Trouble in Paradise, Insulin, Vol 4, No. 2, pp.12, 2009.

[14] Howitt et al., The social distribution of diabetes, hypertension and related risk factors in Barbados: a cross-sectional study. BMJ Open 2015; Vol 5, 2015. DOI:10.1136/bmjopen-2015- 008869

[15] Y. Christiani, T. Dhippayom, N. Chaiyakunapruk, Assessing evidence of inequalities in access to medication for diabetic populations in low- and middle-income countries: a systematic review, Global health action, Vol 9, 32505, 2016. DOI:10.3402/gha. v9.32505

[16] S. Wild, Roglic, Gojka, Green, Anders, Sicree, Richard, King, Hilary, Global Prevalence of Diabetes: Estimates for the Year 2000 and Projections for 2030, Diabetes Care, Vol 27, pp. 1047-53, 2004.

[17] R. Dennis-Bradshaw, Diabetes Self-Management Education for Adults with Type 2 Diabetes Mellitus, Walden Dissertations and Doctoral Studies. 1812. 2015. https://scholarworks.waldenu.edu/dissertations/1812

[18] Pan American Health Organization, Guyana Strategic plan for the integrated prevention and control of chronic non-communicable diseases and their risk factors 2013 2020, Georgetown, 2013.https://www.paho.org/guy/index.p hp?option=com_docman\&view=download\&category_slug= not-communicable\&alias=119-guyana-ncds-strategic-plan-2 013-2020\&Itemid=291

[19] C.D. McNaughton, R. R. Korman, E. K. Kabagambe et al., Health literacy and blood glucose among Guyanese emergency department patients without diagnosed diabetes: a cross-sectional study, Diabetol Metab Syndr Vol 7, pp. 31, 2015. DOI: 10.1186/s13098-015-0028-1

[20] J. Lowe, RG Sibbald, N.Y. Taha, G. Lebovic, C. Martin, I. Bhoj et al., The Guyana Diabetes and Foot Care Project: A Complex Quality Improvement Intervention to Decrease Diabetes-Related Major Lower Extremity Amputations and Improve Diabetes Care in a Lower-Middle-Income Country, PLoS Med, Vol. 12, No. 4, pp. e1001814, 2015. DOI:10.1371/ journal. pmed.1001814

[21] American Diabetes Association, Standards of medical care in diabetes-2010, Diabetes Care, Vol. 33, Suppl 1, S11-61, 2010. DOI: 10.2337/dc10-S011 PMID: 20042772 
[22] D. Jordan, D. Simpson, R. Kurup, A. Anderson, C. Boston, T.A Pilot Study on Pre-diabetes and Associated Central Obesity among Students of the University of Guyana, Guyana. Asian Journal of Immunology, Vol. 3, No. 1, pp. 39-45, 2020.

[23] H. A. Mitchell, H. Allen, T. Koch, Guyanese expatriate women ask: "is it a touch of sugar?". Action Research, Vol. 18, No.4, pp. 433-447, 2017. DOI: $10.1177 / 1476750317721303$

[24] E. Cummings, A. Khan, J. Singh, V. Raja, A. Defreitas, Knowledge, attitudes and practices of persons diagnosed with type 2 diabetes mellitus with regards to Nephropathy a complication. South American Journal of Public Health, Volume-2, Issue-2, 2014.
[25] Nadège Corine Yessito Houehanou, Ariyoh Salimanou Amidou, Arnaud Joël Djidjoho Sonou, Gwladys Gbaguid, Latifath Ibouraïma, Philippe Lacroix, Dismand Houinato , "Knowledge, Attitudes and Practices towards Hypertension among Hypertensive Patients in Rural Area, Tanvè (Benin)," Universal Journal of Public Health, Vol. 8, No. 4, pp. 120 - 126, 2020. DOI: 10.13189/ujph.2020.080402.

[26] Elizabeth Kateta, Josephine De Villiers, Hermine Iita, "Knowledge, Attitudes and Practices of Patients Diagnosed with Tuberculosis Related to Tuberculosis Treatment Adherence in Keetmanshoop District, Namibia," Universal Journal of Public Health, Vol. 8, No. 2, pp. 43 - 56, 2020. DOI: 10.13189/ujph.2020.080201. 